\title{
Wire arc additive manufacturing of AA5183 with TiC nanoparticles
}

\author{
Geir Langelandsvik $^{1}$ (D) Magnus Eriksson ${ }^{1} \cdot$ Odd M. Akselsen $^{1} \cdot$ Hans J. Roven ${ }^{2}$
}

Received: 8 June 2021 / Accepted: 22 October 2021 / Published online: 13 November 2021

(C) The Author(s) 2021

\begin{abstract}
Aluminium alloys processed by wire arc additive manufacturing (WAAM) exhibit a relatively coarse microstructure with a columnar morphology. A powerful measure to refine the microstructure and to enhance mechanical properties is to promote grain refinement during solidification. Addition of ceramic nanoparticles has shown great potential as grain refiner and strengthening phase in aluminium alloys. Thus, an Al-Mg alloy mixed with TiC nanoparticles was manufactured by the novel metal screw extrusion method to a wire and subsequently deposited by WAAM. Measures to restrict oxidation of magnesium during metal screw extrusion were examined. Purging of $\mathrm{CO}_{2}$ gas into the extrusion chamber resulted in a remarkable reduction in formation of $\mathrm{MgO}$ and $\mathrm{Mg}(\mathrm{OH})_{2}$. TiC decomposed to $\mathrm{Al}_{3} \mathrm{Ti}$ during WAAM deposition, leading to a significant grain refinement of $93 \%$ compared to a commercial benchmark. The presence of remaining TiC nanoparticles accounted for an increased hardness of the WAAM material through thermal expansion mismatch strengthening and Orowan strengthening. Exposure of TiC to moisture in air during metal screw extrusion increased the internal hydrogen content significantly, and a highly porous structure was seen after WAAM deposition.
\end{abstract}

Keywords Metal continuous screw extrusion (MCSE) - Additive manufacturing · Wire arc additive manufacturing $($ WAAM $)$ Aluminium matrix composites $($ AMC) $\cdot$ Grain refinement · Columnar to equiaxed transition $(C E T)$

\section{Introduction}

Research and development related to additive manufacturing (AM) of metals has seen a great rise in recent years. Attractive characteristics like shorter time-to-market, increased material utilisation, novel designs, and improved performance are major driving forces for introduction of AM to industrial applications. The welding-based AM method wire arc additive manufacturing (WAAM) is among

Geir Langelandsvik

geir.langelandsvik@sintef.no

Magnus Eriksson

magnus.eriksson@sintef.no

Odd M. Akselsen

odd.m.akselsen@sintef.no

Hans J. Roven

hans.j.roven@ntnu.no

1 SINTEF Industry, 7491 Trondheim, Norway

2 Department of Materials Science and Engineering, NTNU Norwegian University of Science and Technology, 7491 Trondheim, Norway one of the most heavily studied branches of metal AM. WAAM is relevant for manufacturing of components and structures with larger volumes and with intermediate design complexity [1]. The WAAM system utilises fusion of feedstock wires by an electric arc to create stand-alone products. Pre-programmed robotic manipulation provides strategic deposition of material in a layer-by-layer fashion until the final shape is obtained. WAAM is considered a lowcost AM method with high material and energy utilisation. Investment and material costs are orders of magnitude lower than powder-and-laser based techniques, and nearly $100 \%$ of the input material is used to create the component [2]. Deposition rates can reach several $\mathrm{kg} / \mathrm{h}$ for aluminium, dependent on selected input parameters [2, 3].

According to $\mathrm{Wu}$ et al. [4], porosity and crack susceptibility are two major challenges for WAAM of aluminium. Hydrogen porosity has challenged aluminium engineers and researchers for decades. The main problem is the large difference of hydrogen solubility in aluminium between liquid and solid states. As aluminium in the liquid state can dissolve 20 times more hydrogen than in the solid state [5], supersaturated hydrogen precipitate as bubbles upon solidification. The rapid solidification in AM and WAAM limits gas escape, and pores are commonly observed in the 
structure. Porosity negatively influence mechanical properties, especially fatigue [6]. The porosity content can be restricted and even eliminated in WAAM by using proper wire feedstock with low hydrogen content, low heat input, and suitable post-processing [7-9].

The aluminium alloy selection available for WAAM is restricted to alloys commercialised for traditional arc welding. At present, this includes selected alloys from the $\mathrm{Al}-\mathrm{Cu}$, $\mathrm{Al}-\mathrm{Si}$, and $\mathrm{Al}-\mathrm{Mg}$ series. Crack formation in the final stages of solidification limits the application of many alloys for arc deposition. The combination of long solidification intervals and promotion of an unfavourable columnar grain structure increases the cracking tendency. A columnar dendritic structure limits redistribution of liquid in the two-phase solidification interval, creating locked-in melt pockets. Upon final solidification, these pockets shrink and exert a tensile stress on the columnar dendritic framework. If the residual stresses surpass the tensile strength, long intergranular cracks are created in the as-solidified material [10].

A powerful measure to limit solidification cracking is to promote a favourable equiaxed microstructure during solidification. Equiaxed dendrites enable melt redistribution during the final stages of solidification and possess better resistance to shrinkage stresses due to an increased grain boundary volume. Several measures can be taken to transform the dendritic structure from columnar to equiaxed. The concept of grain refinement by heterogeneous nucleation is a common procedure in casthouses worldwide, but rarely utilised in arc deposition techniques like welding and WAAM [11]. Addition of so-called grain refining master alloys promotes nucleation of primary aluminium ahead of the solidification front. The mechanism is two-folded. Solute alloy elements pile up in front of the solidification front, causing a constitutional undercooled zone. The transient cool zone is paramount for activation of a new aluminium nucleus. Aluminium grains also need a solid substrate to nucleate from, preferably with a low surface energy towards aluminium. In this way, nucleation can initiate with minimum undercooling. Excellent substrates (i.e. nuclei) are broken aluminium dendrite tips [12], ceramic particles like $\mathrm{TiC}$ and $\mathrm{TiB}_{2}$ and intermetallics like $\mathrm{Al}_{3} \mathrm{Ti}$ [13].

This study will introduce $\mathrm{TiC}$ nanoparticles to promote a fine, equiaxed microstructure in the Al-Mg alloy AA5183 manufactured by WAAM. The effect of strength enhancement by the presence of nanoparticles will also be examined and analysed. The novel metal screw extrusion (MSE) method will be used to produce the feedstock material for WAAM. MSE provides a solid-state alternative for manufacturing of aluminium matrix composites with low degree of agglomeration and high versatility in terms of using different alloys and ceramic reinforcements [14].

\section{Materials and methods}

The base material selected for this study was the Al-Mg alloy AA5183. The material was supplied in form of spooled $\varnothing 1.2 \mathrm{~mm}$ wire manufactured by Safra $\mathrm{SPa}$, Italy. The AA5183 material was chosen as base material to envelope the error source of different material origins when comparing the WAAM materials. The chemical composition of AA5183 from inductively coupled plasma mass spectrometry (ICP-MS) is given in Table 1. The AA5183 wire was prepared for MSE by chopping it into granules by a rotating knife. The knife blades were lubricated with grease, which contaminated the aluminium granules. Thus, a cleaning pre-treatment in acetone was performed, followed by thermal drying at $120^{\circ} \mathrm{C}$ for $8 \mathrm{~h}$. A portion of dry AA5183 was mixed with 3 wt.\% TiC nanoparticles (Nanomaterials Inc., diameter 40-60 nm) in a sealed beaker. TiC was vacuum heat treated at $350{ }^{\circ} \mathrm{C}$ for $2 \mathrm{~h}$ prior to mixing. The TiC powder and aluminium granules were placed in a glove box with Ar atmosphere and roll mixed for $48 \mathrm{~h}$ until a black, dense coating was achieved on each granule. Granules with and without TiC-coating were extruded by MSE in a prototype extruder situated at the Norwegian University of Science and Technology (NTNU). A single-flight screw and $\varnothing 10 \mathrm{~mm}$ die opening was used to produce the profiles. The extrusion temperature was $500{ }^{\circ} \mathrm{C}$ and the extruded materials were cooled in air. Sections of the extruded profiles can be seen in Fig. 1a.

Extrusion in air in combination with high temperatures increases the rate of magnesium oxidation. Unlike the dense aluminium oxide, $\mathrm{MgO}$ is porous and enable repeated oxidation at higher temperatures. Solid solution strengthening of $\mathrm{Mg}$ is lost upon formation of $\mathrm{MgO}$, which revert the mechanical properties. Further, $\mathrm{Mg}(\mathrm{OH})_{2}$ is formed in the presence of moisture and increase the overall hydrogen content in the material. An increased hydrogen content will produce hydrogen porosity during WAAM [15]. Measures to restrict magnesium oxidation were thus investigated. An increase of the $\mathrm{CO}_{2}$ partial pressure has shown a beneficial effect to restrict the oxidation of magnesium in aluminium melts [16]. This effect was examined in MSE by purging $\mathrm{CO}_{2}$ gas into the extruder feed hole. In total four parallels were manufactured by metal screw extrusion, with presence of $\mathrm{TiC}$ nanoparticles and $\mathrm{CO}_{2}$ gas shielding as variables.

Table 1 Chemical composition of AA5183 Ø1.2 mm wire in wt.\% [17]

\begin{tabular}{lllllllll}
\hline $\mathrm{Mg}$ & $\mathrm{Mn}$ & $\mathrm{Fe}$ & $\mathrm{Ti}$ & $\mathrm{Cu}$ & $\mathrm{Si}$ & $\mathrm{Zn}$ & $\mathrm{Cr}$ & $\mathrm{Al}$ \\
\hline 4.65 & 0.66 & 0.12 & 0.11 & 0.01 & 0.15 & 0.01 & 0.09 & Balance
\end{tabular}


Fig. 1 Input materials for WAAM from metal screw extrusion. The final wires exhibited a good surface quality
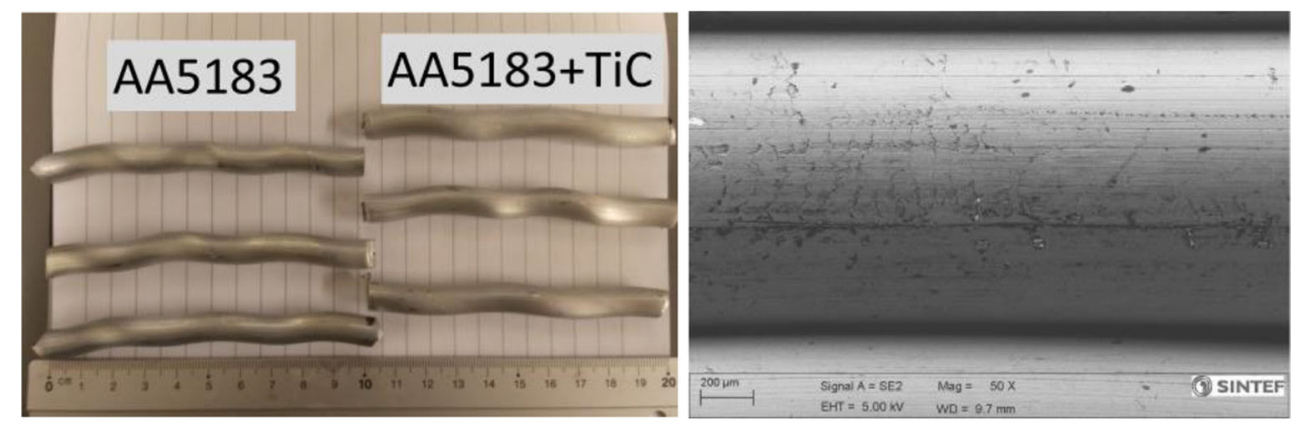

(a) Sections of metal screw extruded $\emptyset 10 \mathrm{~mm}$ (b) Metal screw extruded material after

profiles

wire shaving to $\emptyset 1.2 \mathrm{~mm}$ (SEM)
$\mathrm{CO}_{2}$ gas shielded materials with and without TiC were further processed to $\emptyset 1.2 \mathrm{~mm}$ wires for WAAM. The processing steps involved wire drawing and wire shaving performed by TU Bergakademie Freiberg and Kieselstein $\mathrm{GmbH}$, respectively. Hence, a wire with excellent surface quality was obtained as shown in Fig. 1 b.

WAAM was performed with a Fronius TPS 440i cold metal transfer (CMT) power source. In the CMT process, the arc is short circuited by dipping the wire into the weld pool, which provides better arc stability and less spatter. CMT supplies less energy to the workpiece than conventional electric arc welding, which has been shown desirable for microstructure refinement and porosity reduction [8]. The supplied arc energy $A E$ in these experiments has been calculated through the relation $A E=$ $I U / v$, with input parameters from Table 2 . The dwell time between each deposition layer was $180 \mathrm{~s}$. The target design was a thin wall with length of $150 \mathrm{~mm}$ and height equal 80 $\mathrm{mm}$. An ABB IRB2400 robot manipulator was programmed by the RobotStudio ${ }^{\circledR}$ software to build the walls on $10 \mathrm{~mm}$ thick rolled plates of AA6082-T6. Three feedstock wires were used for WAAM, i.e. wires of commercial AA5183, metal screw extruded AA5183, and metal screw extruded AA5183 with TiC.

The properties of WAAM materials were analysed in terms of microstructure and mechanical properties. Microstructure was examined by light optical microscopy and field emission scanning electron microscopy (SEM).

Table 2 CMT input parameters for WAAM of AA5183

\begin{tabular}{ll}
\hline Parameter & Numerical value \\
\hline Current $I(\mathrm{~A})$ & 85 \\
Voltage $U(\mathrm{~V})$ & 16.6 \\
Travel speed $v(\mathrm{~m} / \mathrm{min})$ & 0.48 \\
Wire feed speed $(\mathrm{m} / \mathrm{min})$ & 5.0 \\
Arc energy $A E(\mathrm{~J} / \mathrm{m})$ & 176 \\
\hline
\end{tabular}

The element distribution and phases were detected by electron dispersive spectroscopy (EDS) mapping. Average grain size was determined by electron backscatter diffraction (EBSD). Vickers microhardness measurements were performed with 100 gram force $\left(\mathrm{HV}_{0.1}\right)$. The porosity content in the WAAM walls was analysed by X-ray computed tomography (CT, Zeiss Metrotom 1500). The pore content of a $60 \times 60 \times 90 \mathrm{~mm}^{3}$ volume in each material was examined and post-processed by the open-source software ImageJ. Hydrogen content in selected materials from MSE was investigated by AlSCAN ${ }^{\mathrm{TM}}$. Thermogravimetric analysis (TGA) of TiC was performed in a TGA-DTA Setaram Sensis system with $99 \%$ Ar atmosphere.

\section{Results and discussion}

\subsection{Metal screw extruded materials}

Macrographs of the four material combinations produced by metal screw extrusion are shown in longitudinal section in Fig. 2. When increasing the $\mathrm{CO}_{2}$ partial pressure in the extrusion chamber, fewer black spots were observed in the material. These constituents are pores and $\mathrm{MgO} . \mathrm{CO}_{2}$ seem to have a beneficial effect on the AA5183 material. Further, the porosity content increased with presence of TiC. The effect of $\mathrm{TiC}$ on the structure will be discussed later.

The effect of $\mathrm{CO}_{2}$ gas shielding was further investigated by hydrogen measurements of metal screw extruded AA5183 materials without TiC (Fig. 3a). TiC-containing materials were excluded from the analysis due to the risk of elevated hydrogen contents which could damage the AlSCANTM equipment. A decrease in hydrogen content of $88 \%$ was found with presence of $\mathrm{CO}_{2}$ in the extrusion chamber, from 21.6 to $2.6 \mathrm{ppm}$.

Magnesium oxide has a high affinity to hydrogen which can be picked up from moisture in air through Reaction (1) [18]. Magnesium hydroxide increases the total hydrogen 
Fig. 2 Metal screw extruded $\varnothing 10 \mathrm{~mm}$ bars in longitudinal section. TiC produces pores in the structure. Presence of $\mathrm{CO}_{2}$ shield gas in the extrusion chamber limited the formation of oxides and pores

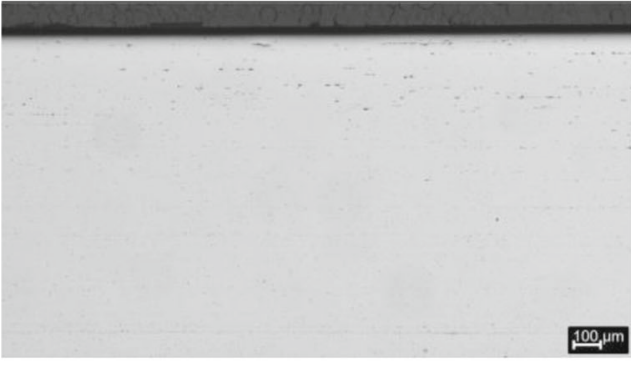

(a) AA5183 without $\mathrm{CO}_{2}$ shield gas

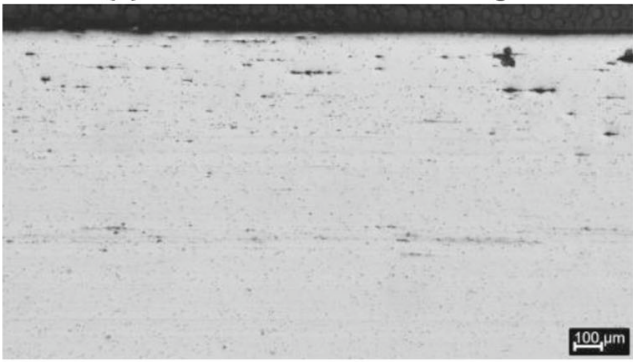

(c) AA5183-TiC without $\mathrm{CO}_{2}$ shield gas

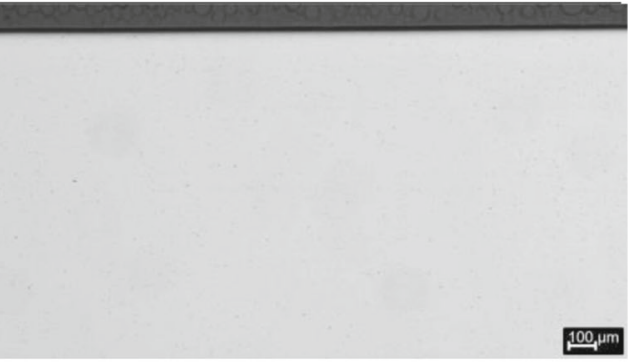

(b) AA5183 with $\mathrm{CO}_{2}$ shield gas

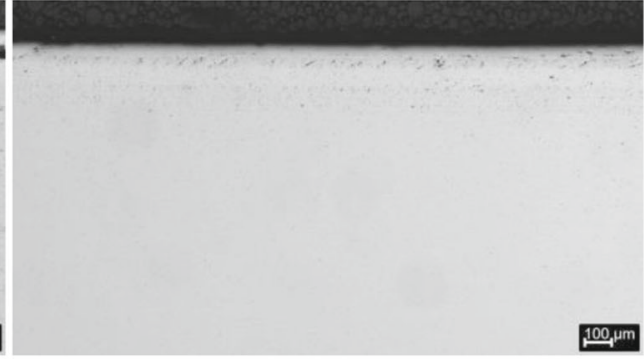

(d) AA5183-TiC with $\mathrm{CO}_{2}$ shield gas content in the aluminium material, which is detrimental for high-quality WAAM due to the formation of gas pores. To restrict hydroxidation of the material, magnesium oxide formation must be inhibited in the first place. $\mathrm{CO}_{2}$ has been demonstrated as an effective measure to restrict the

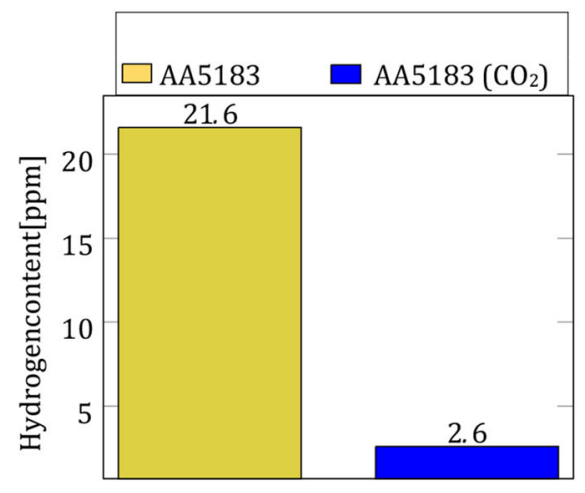

(a) Hydrogen measurements of $\emptyset 10 \mathrm{~mm}$ metal screw extruded profiles of AA5183. The use of $\mathrm{CO}_{2}$ shielding gas in the extrusion chamber reduced the internal hydrogen content by $88 \%$ oxidation of $\mathrm{Mg}$. However, the hydrogen content was still too high for high-quality WAAM deposition. It should be noted that the $\mathrm{CO}_{2}$ gas shielding was primitive in the metal screw extruder, and later improvements should increase the partial pressure of $\mathrm{CO}_{2}$ in the extrusion chamber. Studies

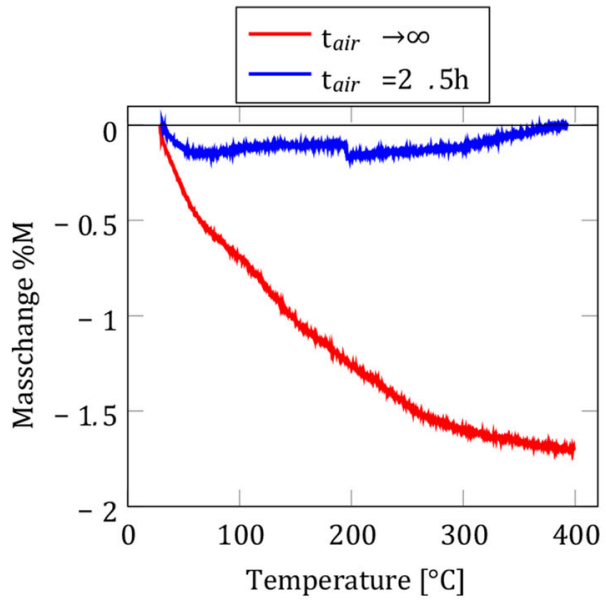

(b) Thermogravimetric analysis of $\mathrm{TiC}$ nanoparticles. Prolonged exposure of TiC to air charged the particles with hydrogeneous compounds

Fig. 3 AlSCAN ${ }^{\mathrm{TM}}$ measurements of metal screw extruded AA5183 profiles and thermogravimetric measurements of TiC nanoparticles to assess the hydrogen content in the raw materials for WAAM 
have shown that a $5 \%$ partial pressure of $\mathrm{CO}_{2}$ in the local atmosphere is sufficient for efficient shielding of $\mathrm{Al}-\mathrm{Mg}$ alloys with high magnesium content $[16,19]$.

$\mathrm{MgO}(\mathrm{s})+\mathrm{H}_{2} \mathrm{O}(\mathrm{l})->\mathrm{Mg}(\mathrm{OH})_{2}(\mathrm{~s})$

Thermogravimetry was used to assess the effect of TiC on the hydrogen content. The $\mathrm{TiC}$ nanopowder was stored in air for several months $\left(t_{\text {air }} \rightarrow \infty\right)$. Thus, the powder had time to adsorb oxides and moisture on the particle surface. These constituents (either physiosorbed or chemisorbed) are believed to evaporate at relatively low temperatures in an inert atmosphere. To examine the evaporation of such species, thermogravimetry between 20 and $400{ }^{\circ} \mathrm{C}$ on TiC nanopowders stored in air was performed. As seen by the red line in Fig. 3b, 1.7\% of the total powder mass was lost up to $400{ }^{\circ} \mathrm{C}$. The sample was not analysed by chromatography to characterise the species that were released. However, it is reason to believe that a major part was hydrogenous compounds like hydroxides and moisture. The importance of a correct pre-treatment and storage of nanoparticles has therefore been demonstrated.

After thermogravimetric measurements at $400{ }^{\circ} \mathrm{C}$, the TiC powder sample was stored in air for $2.5 \mathrm{~h}$ to verify if any moisture or oxygen could re-adsorb on the particle surfaces. After $2.5 \mathrm{~h}$ the sample was again measured by TGA. A mass loss less than $0.2 \%$ was recorded, as seen in Fig. $3 b$ (blue line). Thus, the TiC nanopowders may survive air exposure for a short amount of time, e.g. during metal screw extrusion. A minor mass gain was detected above $300^{\circ} \mathrm{C}$. This effect is probably caused by a reaction between $\mathrm{TiC}$ and impurity gases in the TGA system, e.g. $\mathrm{O}_{2}[20]$.

Figure 4a shows that $\mathrm{TiC}$ nanoparticles were evenly distributed in the AA5183 matrix after metal screw extrusion. The inter-particle distance was estimated to $\sim 1 \mathrm{~mm}$. Observed TiC particles were clustered to a size of $\sim 100$ $\mathrm{nm}$, an increase from the original diameter of 40-60 nm. Agglomerated particles were observed on TiC-coated granules after roll mixing, i.e. before MSE. Hence, metal screw extrusion induces a low degree of agglomeration of the nanoparticles. Magnesium oxides were found evenly dispersed in all materials. The presence of oxides is expected even for $\mathrm{CO}_{2}$ shielded materials, as the partial pressure of $\mathrm{CO}_{2}$ is believed to be relatively low [21].

\subsection{WAAM materials}

Three material parallels were manufactured by CMTWAAM. Polarised light optical macrographs in the frontal section of all deposited materials can be seen in Fig. 5ac. The commercial AA5183 benchmark in Fig. 5a exhibited an equiaxed grain morphology and no macroporosity. The metal screw extruded AA5183 material possessed a columnar grain structure and a few macroscopic pores
(Fig. 5b). The AA5183-TiC material had a very fine grain structure not distinguishable in the macrograph in Fig. 5c. In addition, numerous macro- and micropores can be seen.

$1 \times 1 \mathrm{~mm}^{2}$ EBSD scans of the WAAM materials are shown in Fig. 5d-f. The grain area distribution based on the EBSD scans is shown in Fig. 6. The commercial AA5183 material possessed an average grain area of 2118 $\mathrm{mm}^{2}$. The equiaxed grain morphology originated due to solute partitioning ahead of the growth front during solidification. The corresponding constitutional supercooling was sufficiently large to activate a nucleus ahead of the growth front, possibly particles or dispersoids. As seen from the chemical composition of AA5183 in Table 1, $\sim 0.10 \mathrm{wt} . \%$ titanium is present in the alloy. Solute titanium has a strong segregating effect in aluminium [22]. It is therefore probable that magnesium in combination with titanium is promoting the equiaxed grain morphology.

The metal screw extruded AA5183 material possessed a columnar grain structure (Fig. 5e). The average grain area increased to $4028 \mathrm{~mm}^{2}$. The morphology transition and grain coarsening are not believed to stem from a different temperature field in the melt, as the supplied heat input was identical for all WAAM materials. However, the partitioning conditions may have changed in the material due to oxidation of species. It is highly probable that metal screw extrusion induced oxidation of $\mathrm{Mg}$ into $\mathrm{MgO}$, and possibly Ti into $\mathrm{TiO}_{2}$. The solute partitioning effect is therefore decreased, lowering the probability for heterogeneous nucleation in the melt.

The material reinforced with $\mathrm{TiC}$ exhibited a refined microstructure compared to the commercial counterpart. In fact, the average grain area was reduced by $93 \%$, from 2118 to $151 \mu^{2}$. The grain refinement was caused by heterogeneous nucleation on titanium species in the melt. The phase responsible for the nucleation is believed to be the $\mathrm{Al}_{3} \mathrm{Ti}$ intermetallic which was detected by EDS, see Fig. 7a. The $\mathrm{Al}_{3} \mathrm{Ti}$ phase is created during WAAM on behalf of TiC according to Reaction (2). Thermodynamic calculations of the Gibbs energy of Reaction (2) indicate that $\mathrm{Al}_{3} \mathrm{Ti}$ is thermodynamically stable $(\Delta G<0)$ on behalf of $\mathrm{TiC}$ below $780{ }^{\circ} \mathrm{C}$ [23]. Thus, it is feasible that $\mathrm{TiC}$ decomposes to $\mathrm{Al}_{3} \mathrm{Ti}$ in the melt pool before solidification of primary aluminium initiates at $\sim 600{ }^{\circ} \mathrm{C}$. $\mathrm{Al}_{3} \mathrm{Ti}$ has a low lattice misfit towards primary aluminium as shown by Zhang et al. [13], and thus need low supercooling to be activated as a nucleus. The large particle size of $\sim 2 \mathrm{~mm}$ also decreases the activation energy, as given by Greers free growth model [24]. The petal-like morphology of the intermetallic phase was formed due to the rapid cooling rate in WAAM [25]. Some TiC nanoparticles survived the WAAM deposition and flowed on the advancing solid/liquid interface due to the poor wetting between aluminium and $\mathrm{TiC}[26,27]$. Investigations of the pore interior showed that 
Fig. 4 SEM micrograph of AA5183+TiC MSE material in longitudinal section. The presence of evenly spread $\mathrm{TiC}$ particles is shown
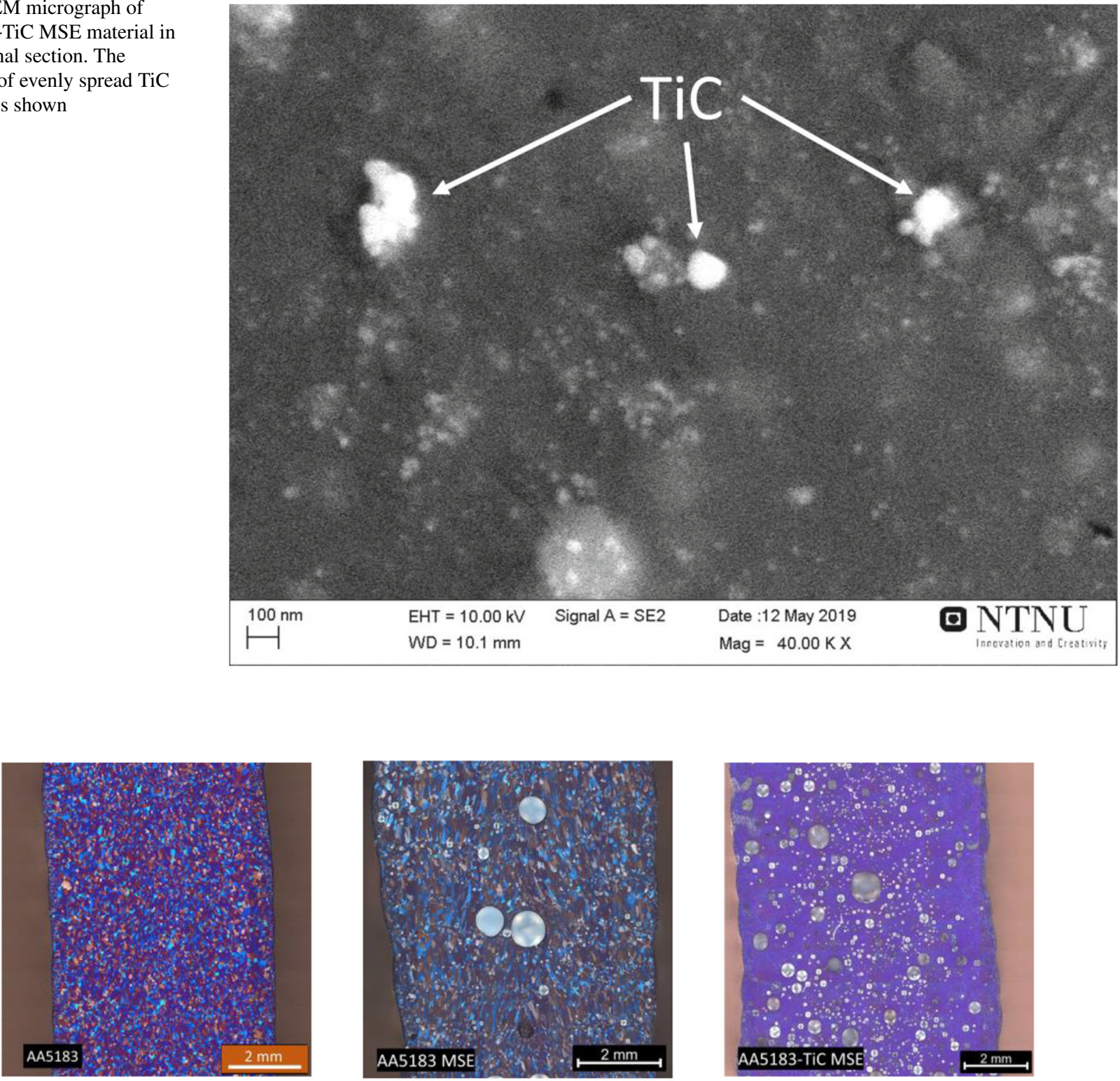

(a) Commercial AA5183
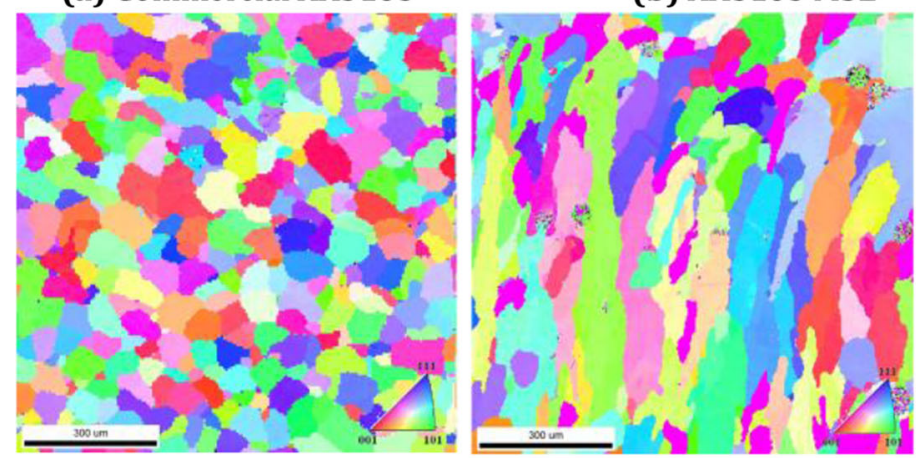

(e) AA5183 MSE (c) AA5183-TiC MSE

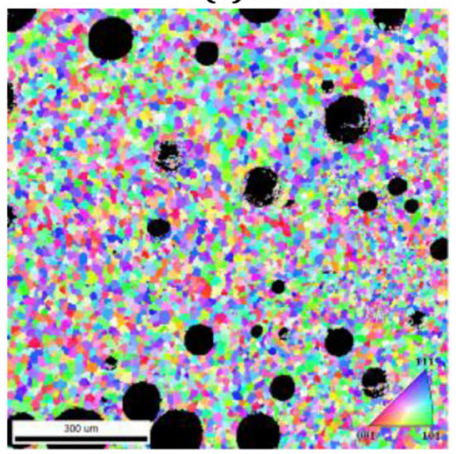

(f) AA5183-TiC MSE

Fig. 5 Grain structure after WAAM deposition (frontal view). AA5183 mixed with TiC resulted in significant grain refinement and porosity formation 
Fig. 6 Grain area distribution of the investigated WAAM materials. The TiC-reinforced material exhibited no grains larger than $1,000 \mu \mathrm{m}^{2}$. The plots are based on EBSD data from Fig. 5

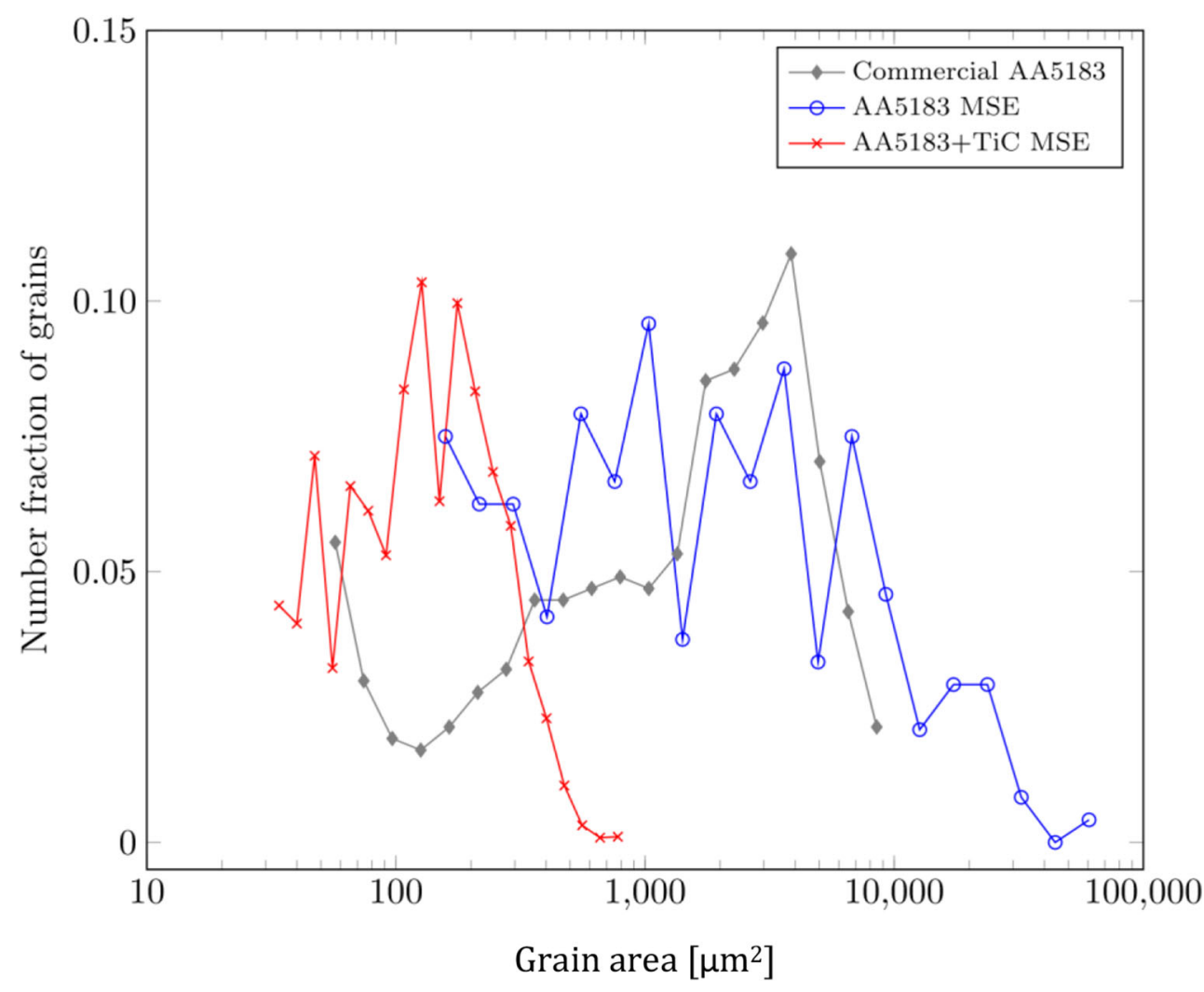

TiC nanoparticles and hexagonal $\mathrm{MgO}$ were allocated on the grain boundaries (Fig. 7b).

$$
13 \mathrm{Al}+3 \mathrm{TiC}=3 \mathrm{Al}_{3} \mathrm{Ti}+\mathrm{Al} 4 \mathrm{C} 3
$$

Arc deposition of aluminium alloys mixed with $\mathrm{TiC}$ particles has gained increasing attention in later years. Reported results related to grain refinement and chemical stability of $\mathrm{TiC}$ are in opposition to the results presented in this work. Jin et al. [28] utilised interlayer spraying of TiC microparticles in WAAM of AA2219. The TiC particles survived the melting cycle, as no $\mathrm{Al}_{3} \mathrm{Ti}$ was observed. A possible explanation for this result is the particle size of 5 $\mathrm{mm}$, which increased the thermal stability of TiC. A modest grain refinement was reported, supposedly due to nucleation on TiC clusters.

In the works of Zuo et al. [29] and Sokoluk et al. [11], the Al-Zn-Mg-Cu AA7075 alloy was reinforced with TiC nanoparticles. In fact, the $\mathrm{TiC}$ nanoparticles were identical to the compound used in this study (diameter 40-60 nm, US Research Nanomaterials). Contrary to our study, the TiC nanoparticles survived the melt cycle which involved casting at $830{ }^{\circ} \mathrm{C}$ and subsequent arc welding. A refined grain structure was attributed to nucleation on $\mathrm{TiC}$ nanoparticles. The survival of $\mathrm{TiC}$ nanoparticles in aluminium may be related to the use of fluxing agents to increase the wettability. Liu et al. [30] found that potassium tetrafluoaluminate $\left(\mathrm{KAlF}_{4}\right)$ exhibited promising properties as fluxing agent. Thus, TiC-inoculated aluminium alloys may require a flux to survive in additive manufacturing.

The grain refining effect by introduction of ceramic nanoparticles is vital for the expansion of the alloy selection for WAAM. Currently, less than a dozen aluminium alloys are available as feedstock for WAAM [31]. The selection is highly restricted due to the solidification cracking susceptibility which pesters several aluminium systems. Components crack in WAAM due to the formation of a columnar dendritic network with limited ability for melt distribution. Grain refinement transforms this dendritic network into fine equiaxed crystals with enhanced melt distribution. Further, the increased grain boundary area distributes the shrinkage stresses associated with aluminium solidification, which further decreases the cracking susceptibility. The powerful grain refinement demonstrated in this study could therefore be translated to other alloy systems like 6xxx- and 7xxx-alloys for crackfree WAAM deposition.

CT scans of the WAAM walls in the frontal section are shown in Fig. 8a-c. The commercial AA5183 wall showed a relatively low amount of porosity where all pores had a spherical morphology. The porosity stems from evaporation of different species, mainly $\mathrm{H}_{2}$ and possibly $\mathrm{Mg}$. The pores were concentrated in bands along the fusion boundaries. Precipitated hydrogen pores float up due to buoyancy, where it either escapes the melt pool or is trapped by the 
Fig. 7 SEM micrographs of AA5183+TiC WAAM material
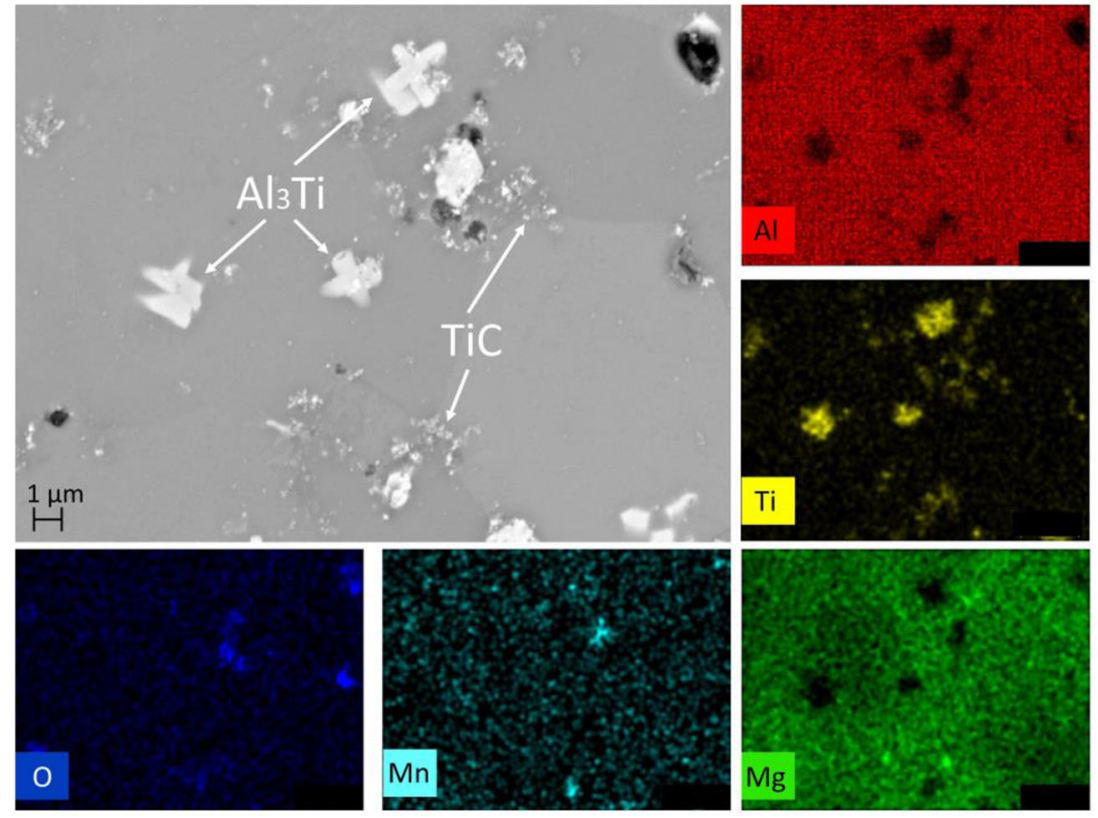

(a) SEM backscatter micrograph showing presence of $\mathrm{TiC}$ on grain boundaries and $\mathrm{Al}_{3} \mathrm{Ti}$ in grain centres. Corresponding EDS maps of $\mathrm{Al}, \mathrm{Ti}, \mathrm{Mg}, \mathrm{Mn}$, and $\mathrm{O}$ are inserted.

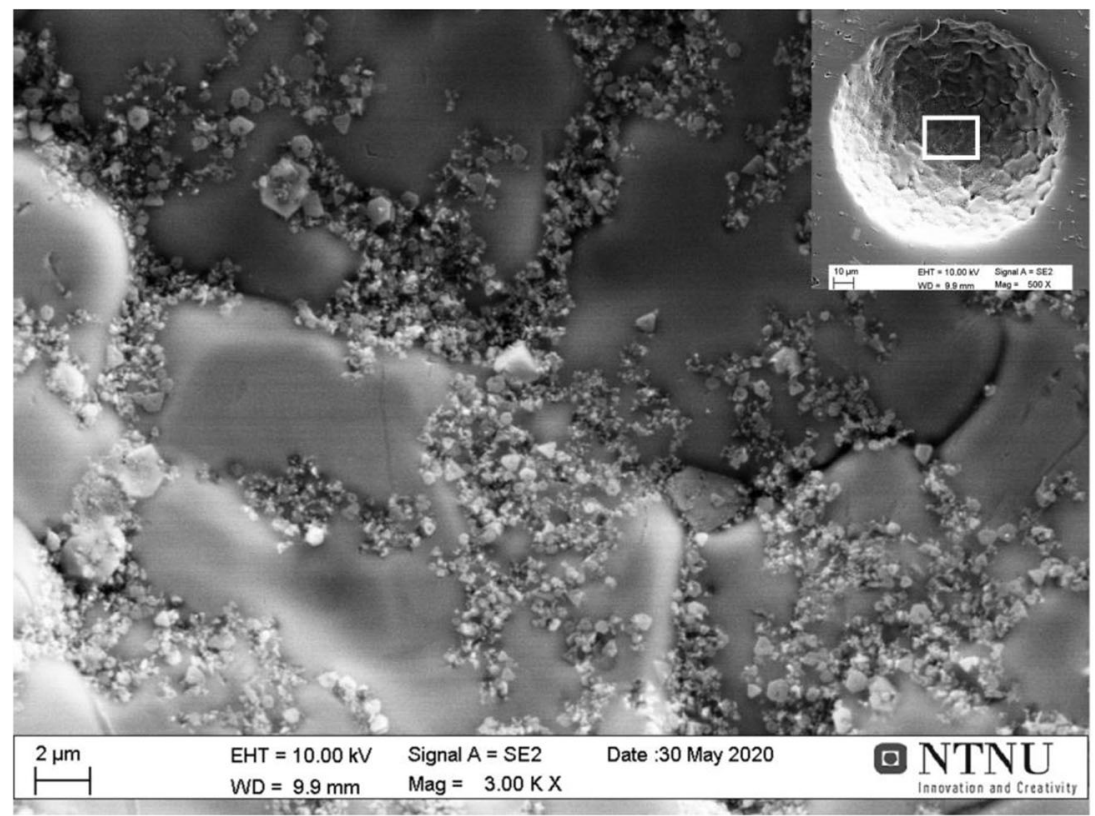

(b) Tiny $\mathrm{TiC}$ nanoparticles and hexagonal MgO oxides inside pores. Constituents are accumulated on the grain boundaries. Low-magnification image of the pore is inserted in right top corner. solidification front. Ultimately, this region of gas pores is distributed along the top of the newly solidified layer. When this layer is remelted upon deposition of a subsequent layer, the gas pores are re-dissolved into the liquid and instantly re-precipitated upon start of solidification. Due to the large cooling rate at the bottom of the melt pool, these pores are trapped, and the banding pore structure is created.

A similar pore banding structure can be seen in the metal screw extruded AA5183 material in Fig. 8b. However, the density and size of pores were increased due to the rel- 
Fig. 8 Computed tomography scans of AA5183 thin walls manufactured by WAAM. The porosity content increased with processing through metal screw extrusion and addition of $\mathrm{TiC}$ nanoparticles

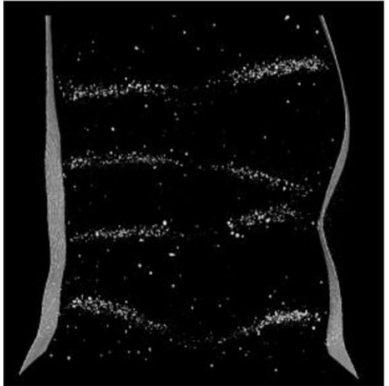

(a) Commercial AA5183

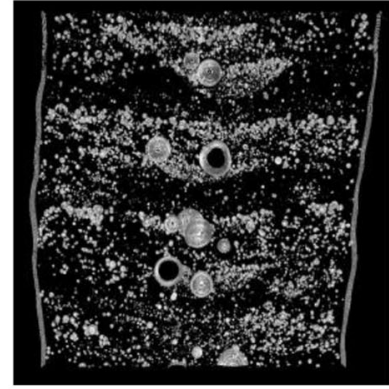

(b) AA5183 MSE

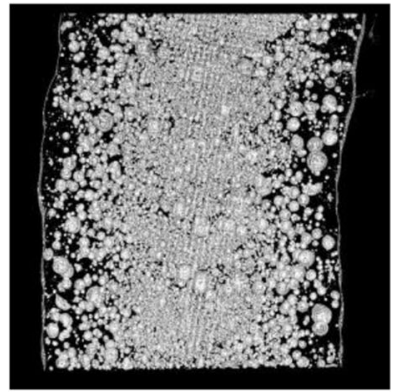

(c) AA5183-TiC MSE

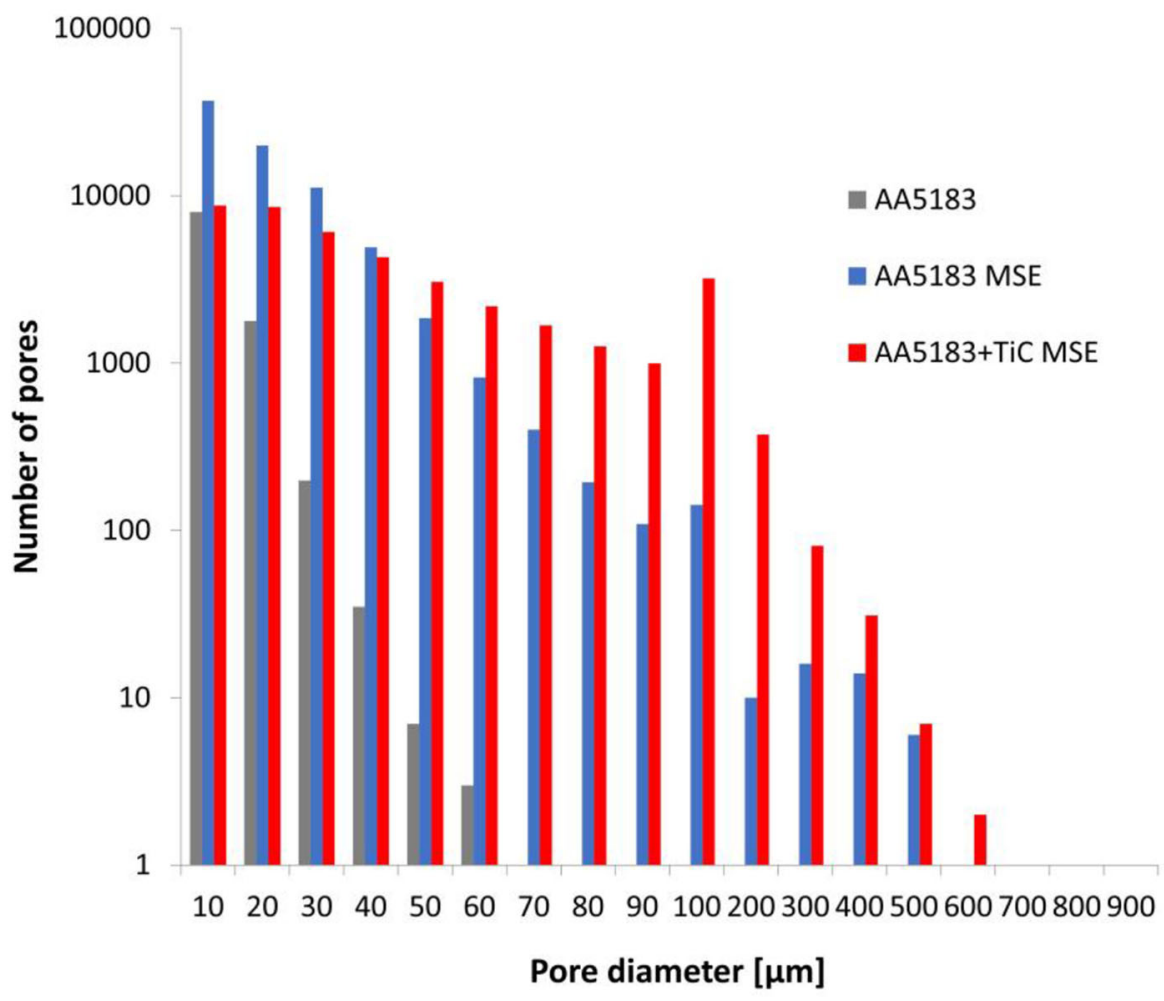

(d) Porosity statistics from CT scans of a $60 \times 60 \times 90 \mathrm{~mm}^{3}$ volume

atively high hydrogen content. A mixture of macro- and microporosity was observed, which indicates that the solubility of hydrogen had been surpassed when the aluminium was in liquid state [32]. The MSE AA5183 material had a hydrogen content of $\sim 2.6 \mathrm{ppm}$ as shown in Fig. 3a. The aluminium melt was therefore supersaturated with hydrogen at around $850^{\circ} \mathrm{C}$ [5]. The excess hydrogen in the liquid melt pool is believed to create the macroporosity on solid interfaces in the melt pool, e.g. inclusions.

The AA5183-TiC material exhibited a highly porous structure, as seen in Fig. 8c. The increased hydrogen level due to the addition of $\mathrm{TiC}$ induced large-scale formation of macroporosity. In fact, the presence of numerous solid interfaces of $\mathrm{TiC}$ in the melt pool facilitated the nucleation and growth of pores in the liquid. The vacuum treatment of TiC nanoparticles prior to MSE was inefficient in reducing the porosity content. The nanoparticles were exposed to air for $<2.5 \mathrm{~h}$ during the MSE experiment. Short-term exposure of $\mathrm{TiC}$ to air is therefore sufficient for readsorption of moisture on the $\mathrm{TiC}$ particle surface. The high temperatures in the metal screw extrusion machine surpassing $500{ }^{\circ} \mathrm{C}$ may accelerate the adsorption. The pore statistics of a $60 \times 60 \times 90 \mathrm{~mm}^{3}$ volume of each material in Fig. 8d underpin that metal screw extrusion at present 
create an elevated pore content, especially in the presence of TiC. Future developments of the metal screw extrusion technology will require better protection of the input materials to enhance the material quality.

Tensile testing of metal screw extruded materials exhibited premature fracture due to the high porosity content
(Fig. 9a). The effective load bearing surface was excessively reduced for the most porous samples, which influenced the yield strength and elongation significantly. The commercial AA5183 WAAM material exhibited comparable mechanical properties to data reported in the literature [33-35]. A pronounced anisotropy in elongation between tensile samples
Fig. 9 Mechanical properties of WAAM materials from commercial and metal screw extruded feedstock. Material manufactured through metal screw extrusion experienced premature fracture due to high pore density. The hardness increased by addition of TiC due to grain refinement and particle strengthening

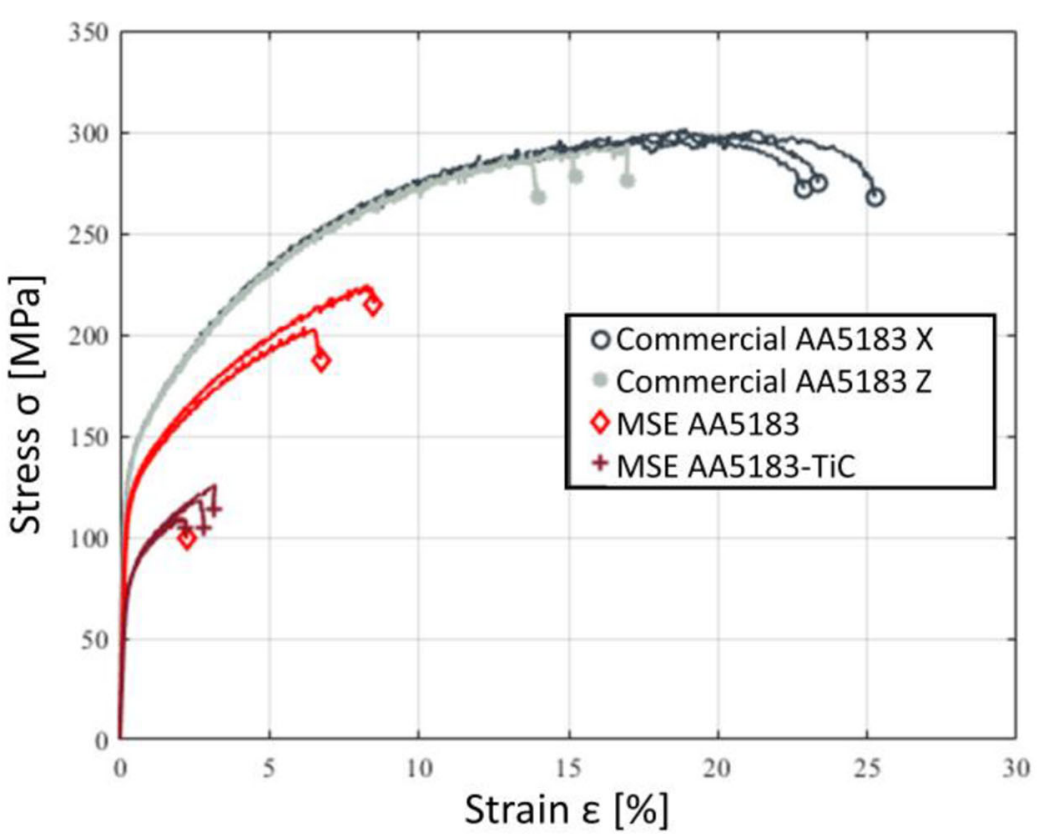

(a) Tensile curves of WAAM materials

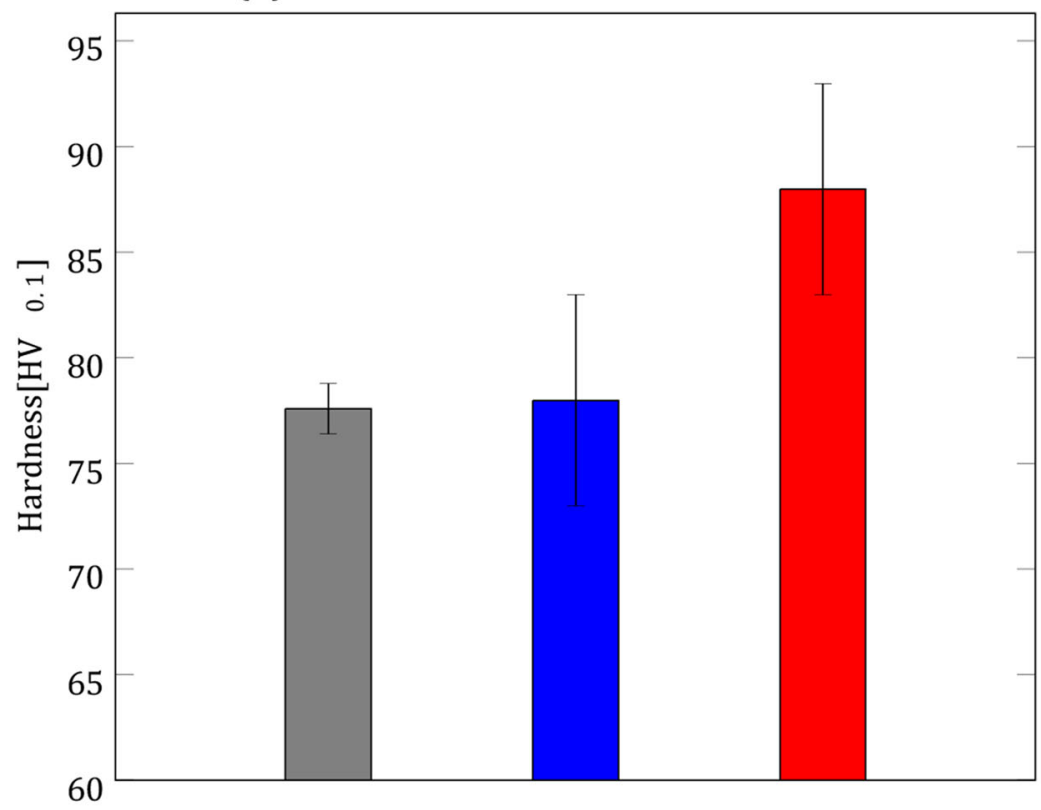

Commercial AA5183 AA5183 MSE AA5183+TiC MSE

(b) Microhardness of materials after WAAM 
oriented transverse $(Z)$ and parallel $(X)$ to the deposition direction was seen. The anisotropy is not a result of grain morphology as proposed by some authors [36]. The earlier onset of fracture in the transverse direction is related to the interlayer pore structure. As the transverse tensile sample cross perpendicular to the interlayer pores, the load bearing capacity was locally reduced. An earlier strain concentration and failure are therefore experienced in tensile specimens oriented perpendicular to the deposition direction $(Z)$.

Vickers microhardness was used as an alternative measure to assess the mechanical properties of the WAAM materials, given in Fig. 9b. The lean AA5183 materials exhibited similar hardness of $78 H V_{0.1}$. The metal screw extruded AA5183 material had a higher standard deviation than the commercial AA5183, probably due to the presence of pores in the structure. The AA5183-TiC material showed an increased hardness, i.e. $89 H V_{0.1}$. The combined effects of a refined grain structure (Hall-Petch strengthening) and particle strengthening (Orowan and CTE) are believed to account for the enhanced hardness [37].

\section{Conclusions}

Microstructural refinement of aluminium is a powerful measure to increase the mechanical properties and expand the alloy selection. Utilisation of ceramic nanoparticles as grain refiner and strengthening phase in WAAM has shown remarkable potential, but efficient production methods are lacking. This study examined the applicability of metal screw extrusion to manufacture nanoparticle reinforced aluminium feedstock for WAAM. Metal screw extrusion has been shown capable to mix and disperse the nanoparticle phase without agglomeration. Further, the effect of $\mathrm{CO}_{2}$ atmosphere during extrusion demonstrated that oxidation of magnesium can be restricted, which is beneficial to restrict the content of oxides and hydroxides. WAAM of an Al$\mathrm{Mg}$ alloy mixed with $\mathrm{TiC}$ exhibited a significant grain refinement, where the average grain area was decreased by $93 \%$ compared to a commercial benchmark. In fact, decomposition of $\mathrm{TiC}$ into the $\mathrm{Al}_{3} \mathrm{Ti}$ intermetallic accounted for the grain refinement through heterogeneous nucleation. The strong grain refining effect is proposed to reduce the cracking susceptibility of aluminium alloys and could open new alloy classes for WAAM. TiC nanoparticles were reactive towards moisture in air during metal screw extrusion and induced excessive porosity formation after WAAM. Amendment to protect the input materials prior to, and during extrusion, is paramount to further adapt the metal screw extrusion technology for WAAM feedstock production.
Acknowledgements The authors would like to acknowledge Dipl.-Ing. Frank Hoffmann and Prof. Dr.-Ing. Ulrich Prahl, TU Bergakademie Freiberg, for their support in wire drawing and wire shaving. Mr. Morten H. Danielsen, Mr. Stein Rørvik, Mrs. Sarina Bao and Mr. Mathieu Grandcolas are acknowledged for their experimental support.

Author contribution G. Langelandsvik: conceptualisation, investigation, methodology, visualisation, writing — original draft, writingreview and editing; M. Eriksson: resources, project administration, supervision; O. Akselsen: validation, project administration, supervision, writing - review and editing; H. Roven: validation, project administration, supervision, writing — review and editing.

Funding Open access funding provided by SINTEF AS. This work was supported by the Research Council of Norway (Contract No. 272402).

Availability of data and material Data and material can be provided upon request.

Code availability Not applicable

\section{Declarations}

Conflict of interest The authors declare no competing interests.

Open Access This article is licensed under a Creative Commons Attribution 4.0 International License, which permits use, sharing, adaptation, distribution and reproduction in any medium or format, as long as you give appropriate credit to the original author(s) and the source, provide a link to the Creative Commons licence, and indicate if changes were made. The images or other third party material in this article are included in the article's Creative Commons licence, unless indicated otherwise in a credit line to the material. If material is not included in the article's Creative Commons licence and your intended use is not permitted by statutory regulation or exceeds the permitted use, you will need to obtain permission directly from the copyright holder. To view a copy of this licence, visit http://creativecommons. org/licenses/by/4.0/.

\section{References}

1. Thompson MK, Moroni G, Vaneker T, Fadel G, Campbell RI, Gibson I, Bernard A, Schulz J, Graf P, Ahuja B et al (2016) Design for Additive Manufacturing: Trends, opportunities, considerations, and constraints. CIRP Ann 65(2):737. https://doi.org/10.1016/j. cirp.2016.05.004

2. Williams S, Martina F, Addison AC, Ding J, Pardal G, Colegrove $\mathrm{P}$, Wire + (2016) Arc additive manufacturing. Mater Sci Technol 32(7):641. https://doi.org/10.1179/1743284715Y.0000000073

3. Langelandsvik G, Horgar A, Furu T, Roven HJ, Akselsen O (2020) Comparative study of eutectic Al-Si alloys manufactured by WAAM and casting. Int $\mathrm{J}$ Adv Manuf Technol:1-13. https://doi.org/10.1007/s00170-020-05735-7

4. Wu B, Pan Z, Ding D, Cuiuri D, Li H, Xu J, Norrish J (2018) A review of the wire arc additive manufacturing of metals: properties, defects and quality improvement. J Manuf Process 35:127. https://doi.org/10.1016/j.jmapro.2018.08.001

5. Ransley CE (1948) The solubility of hydrogen in liquid and solid aluminium. J Inst Met 74:599 
6. Shen F, Zhao B, Li L, Chua CK, Zhou K (2017) Fatigue damage evolution and lifetime prediction of welded joints with the consideration of residual stresses and porosity. Int J Fatigue 103:272. https://doi.org/10.1016/j.ijfatigue.2017.06.014

7. Ryan E, Sabin T, Watts J, Whiting M (2018) The influence of build parameters and wire batch on porosity of wire and arc additive manufactured aluminium alloy 2319. J Mater Process Technol 262:577. https://doi.org/10.1016/j.jmatprotec.2018.07.030

8. Cong B, Ding J, Williams S (2015) Effect of arc mode in cold metal transfer process on porosity of additively manufactured Al-6.3\% Cu alloy. Int J Adv Manuf Technol 76(9-12):1593. https://doi.org/10.1007/s00170-014-6346-X

9. Gu J, Ding J, Williams S, Gu H, Ma P, Zhai Y (2016) The effect of inter-layer cold working and post-deposition heat treatment on porosity in additively manufactured aluminum alloys. J Mater Process Technol 230:26. https://doi.org/10.1016/j.jmatprotec.2015. 11.006

10. Martin JH, Yahata BD, Hundley JM, Mayer JA, Schaedler TA, Pollock TM (2017) 3D Printing of high-strength aluminium alloys. Nature 549(7672):365. https://doi.org/10.1038/nature23894

11. Sokoluk M, Cao C, Pan S, Li X (2019) Nanoparticle-enabled phase control for arc welding of unweldable aluminum alloy 7075. Nat Commun 10(1):1. https://doi.org/10.1038/s41467-01807989-y

12. Zhang C, Gao M, Zeng X (2019) Workpiece vibration augmented wire arc additive manufacturing of high strength aluminum alloy. J Mater Process Technol 271:85. https://doi.org/10.1016/j. jmatprotec.2019.03.028

13. Zhang MX, Kelly PM, Easton M, Taylor JA (2005) Crystallographic study of grain refinement in aluminum alloys using the edge-to-edge matching model. Acta Mater 53(5):1427. https://doi.org/10.1016/j.actamat.2004.11.037

14. Langelandsvik G, Grandcolas M, Skorpen KG, Furu T, Akselsen O, Roven HJ (2020) Development of Al-TiC Wire Feedstock for Additive Manufacturing by Metal Screw Extrusion. Metals 10(11):1485. https://doi.org/10.3390/met10111485

15. Morimoto T, Naono H (1973) Water content on metal oxides. I. Water content on silica gel, magnesium oxide, zinc oxide, and titanium dioxide. Bull Chem Soc Jpn 46(7):2000. https://doi.org/ 10.1246/bcsj.46.2000

16. Smith N, Gleeson B, Saidi WA, Kvithyld A, Tranell G (2018) Mechanism behind the Inhibiting Effect of $\mathrm{CO}_{2}$ on the Oxidation of Al-Mg Alloys. Ind Eng Chem Res 58(3):1434. https://doi.org/ 10.1021/acs.iecr.8b04691

17. Ragnvaldsen $O$ (2019) Characterisation of an aluminium matrix nanocomposite wire manufactured by screw extrusion. Master's thesis, NTNU. http://hdl.handle.net/11250/2624249

18. Ito T, Kuramoto M, Yoshioka M, Tokuda T (1983) Active sites for hydrogen adsorption on magnesium oxide. J Phys Chem 87(22):4411. https://doi.org/10.1021/j100245a019

19. Solem CKW, Ekstrøm KE, Tranell G, Aune RE (2020) In: Light Metals 2020. Springer, pp 1141-1147. https://doi.org/10.1007/ 978-3-030-36408-3_154

20. Voitovich V (1997) Mechanism of the high temperature oxidation of titanium carbide. High Temp Mater Process 16(4):243. https://doi.org/10.1515/HTMP.1997.16.4.243

21. Cochran CN, Belitskus DL, Kinosz DL (1977) Oxidation of aluminum-magnesium melts in air, oxygen, flue gas, and carbon dioxide. Metall Trans B 8(1):323. https://doi.org/10.1007/ BF02657663

22. Easton M, StJohn D (2005) An analysis of the relationship between grain size, solute content, and the potency and number density of nucleant particles. Metall and Mater Trans A 36(7):1911. https://doi.org/10.1007/s11661-005-0054-y
23. Roine A (2018) HSC Chemistry®[Software]. Outotec, Pori. Software available at www.outotec.com/HSC

24. Greer A, Bunn A, Tronche A, Evans P, Bristow D (2000) Modelling of inoculation of metallic melts: application to grain refinement of aluminium by Al-Ti-B. Acta Mater 48(11):2823. https://doi.org/10.1016/S1359-6454(00)00094-X

25. Arnberg L, Bäckerud L, Klang H (1982) Intermetallic particles in Al-Ti-B-type master alloys for grain refinement of aluminium. Metals Technol 9(1):7. https://doi.org/10.1179/ 030716982803286368

26. Aguilar E, León C, Contreras A, López V, Drew R, Bedolla E (2002) Wettability and phase formation in TiC/Alalloys assemblies. Compos A: Appl Sci Manuf 33(10):1425. https://doi.org/10.1016/S1359-835X(02)00160-4

27. Leon C, Lopez V, Bedolla E, Drew R (2002) Wettability of TiC by commercial aluminum alloys. J Mater Sci 37(16):3509. https://doi.org/10.1023/A:1016523408906

28. Jin P, Liu Y, Sun Q (2021) Evolution of crystallographic orientation, columnar to equiaxed transformation and mechanical properties realized by adding TiCps in wire and arc additive manufacturing 2219 aluminum alloy. Add Manuf 39:101878. https://doi.org/10.1016/j.addma.2021.101878

29. Zuo M, Sokoluk M, Cao C, Yuan J, Zheng S, Li X (2019) Microstructure Control and Performance Evolution of Aluminum Alloy 7075 by Nano-Treating. Sci Rep 9(1):1. https://doi.org/10.1038/s41598-019-47182-9

30. Liu W, Cao C, Xu J, Wang X, Li X (2016) Molten salt assisted solidification nanoprocessing of Al-TiC nanocomposites. Mater Lett 185:392. https://doi.org/10.1016/j.matlet.2016.09.023

31. Langelandsvik G, Akselsen O, Furu T, Roven HJ (2021) Review of aluminium alloy development for wire arc additive manufacturing. Materials

32. Kutsuna M, Yan Q (1998) Study on porosity formation in laser welds in aluminium alloys (Report 1): Effects of hydrogen and alloying elements. Weld Int 12(12):937. https://doi.org/10.1080/ 09507119809448539

33. Horgar A, Fostervoll H, Nyhus B, Ren X, Eriksson M, Akselsen O (2018) Additive manufacturing using WAAM with AA5183 wire. J Mater Process Technol 259:68. https://doi.org/10.1016/j. jmatprotec.2018.04.014

34. Fang X, Zhang L, Chen G, Dang X, Huang K, Wang L, Lu B (2018) Correlations between Microstructure Characteristics and Mechanical Properties in 5183 Aluminium Alloy Fabricated by Wire-Arc Additive Manufacturing with Different Arc Modes. Materials 11(11):2075. https://doi.org/10.3390/ma11112075

35. Gierth M, Henckell P, Ali Y, Scholl J, Bergmann J (2020) Wire Arc Additive Manufacturing (WAAM) of Aluminum Alloy AlMg5Mn with Energy-Reduced Gas Metal Arc Welding (GMAW). Materials 13(12):2671. https://doi.org/10.3390/ ma13122671

36. Yehorov Y, da Silva LJ, Scotti A (2019) Exploring the use of switchback for mitigating homoepitaxial unidirectional grain growth and porosity in WAAM of aluminium alloys. Int $\mathbf{J}$ Adv Manuf Technol 104(1-4):1581. https://doi.org/10.1007/s00170019-03959-w

37. Sanaty-Zadeh A (2012) Comparison between current models for the strength of particulate-reinforced metal matrix nanocomposites with emphasis on consideration of Hall-Petch effect. Mater Sci Eng A 531:112. https://doi.org/10.1016/j.msea.2011.10.043

Publisher's note Springer Nature remains neutral with regard to jurisdictional claims in published maps and institutional affiliations. 